\title{
The Research of Military Academy's Current Situation about Administration Education and Job Function
}

\author{
Yu Feng, Hua Zhang, Yiyuan Che, Yan Wang \\ Ordnance Engineering College Department of equipment command and management, \\ Shijiazhuang 050003, China \\ 546665744@qq.com
}

Keywords: Military Academy, Personnel Training, Management Education.

\begin{abstract}
The work about administration and education is an overall fundamental and regular work of military academies. And the military academy is the base of training high-quality military personnel of a new type that under the new situation and latest stage. It is also the wellspring of heightening the army's combat effectiveness and achieving strong military objectives. Therefore, the military academy must make a correct understanding about the basic function of management continuously education work and a profound understanding about the mistakes in educational work. Lessons must be learned from the past. Moreover, it's best to focus on modern information-based war's objective requirement for military talents. Educating people should be the center, and improving the quality of education management.
\end{abstract}

\section{Introduction}

The military personnel training objectives have experienced profound changes and put forward high requirement for the military academy management education due to the limitations on the outdated management theories and misunderstandings in management methods along with the comprehensive promotion of military reforming with Chinese characteristics, the deepening reform of national defense and military system mechanism and the quick development of equipment and weapons. Therefore, some measures and ideas are concluded to improve the overall quality of military academy management education through the investigation and relevant summary.

\section{Basic Function of Military Academy Management Education}

Military academy is the base and source to cultivate high-quality new military talents, and also the basis of army construction and development, while "management education" is the basic method of military academy education. Unlike local colleges, military academies undertake different basic functions and mission and the core task is to train high-quality new military talents, which mainly include "education, demonstration, constraint and innovation" functions.

\subsection{Educational Function of Academy Management}

The educational function of military academy management is its core and position, and focuses on cultivating military talents.Its educational function often combines education with personnel training closely in practical application and operation, and education itself is a management in many management processes.

\subsection{Demonstration Function of Academy Management}

Another is the role of leadership in the modern army construction in addition to the military personnel cultivation and its education and innovation model have determined the role model. Therefore, the good academic atmosphere, high-standard management and high-quality education created by the academy management education actually play an imperceptible cultivation and demonstration role in the psychology, behavior, capability and quality of grassroots students in addition to the strict management following the law. 


\subsection{Constraint Function of Academy Management}

The constraint function of the military academy management is the basis for the regular development of military education, and the prerequisite and guarantee to better adapt to the military environment and realize the stable, orderly and efficient internal operation. And strengthening the strict management, building the management thinking and improving their management and constraint are the urgent needs to enhance the management level of academies, but the inevitable requirements to improve the school quality and better cultivate high-quality military personnel.The combination of regular management education with the teaching process can effectively guarantee the academy management and improve the scientific and standardized management; and only the effective management according to law can ensure the smooth operation of academy education and better promote the education, thus creating an orderly, harmonious and efficient military personnel cultivation environment and ensuring the smooth teaching.

\subsection{Innovative function of academy management}

Based on carrying forward the excellent tradition, the innovation of academy management is to adapt to the requirements of the times, broaden the educational vision, optimize the talent training mode, update the teaching contents, adjust disciplines and reform education management system to seek greater development.

\section{Misunderstanding of military academy management education}

\subsection{In-harmony between management and education}

Nowadays some modern academy education models fail to recognize the dialectical unity between management and education, tend to separate them and mainly reflect in two aspects, the first is two extremes, strictly and rigidly conducting mandatory management and ignoring the mental education, or emphasizing humanized management, giving up principles and reducing the standard requirements; the second is their different subordinates, meaning to regard the top management as the local administrative management staff, management as the work of functional and administrative departments unilaterally and even the responsibilities of political leaders and not related to the administration, leading in uncoordinated and inharmonious working implementation.

\subsection{Ignoring the Systematicness of Management Education}

Military management education is an organic unified system that includes many interaction and interdependence elements and levels, however, many people in the actual process of education management ignore the connection, lack the systematic management ideas, and fail to combine the education management of relevant departments with other aspects and consider its role in the annual plan according to the reality;some focus on the work of their own departments and units, fail to cooperate and coordinate the overall education management, and lack effective unity;and some even mistakenly believe that formal and strict management actually limits the innovative thinking and talents cultivation and form "emphasis on teaching and ignorance of management",which can easily lead to the lack of working enthusiasm and confidence in managers, and ultimately the difficulty to carry out work.

\subsection{Ignoring the Development of Management Education}

The management education is a dynamic development process, and failing to realize the changes in management objects, environments and conditions, rigid management thinking of educators, lack of innovation, outdated and traditional education methods can only form the empty talk; especially the backward management education system can lack the effective guidance for the actual work and lead to the in-harmony between management education and the overall academy construction, and even grass-root education.And these are main reasons for the difficult development and ineffective achievements of management education.

\subsection{Ignoring the Core Task of Management Education}

The lack of correct understanding of the status and role of military academy management education and ignorance of the core task of cultivating talents, and the great emphasis on"manpower,material and financial resources and the units", mechanical management and construction instead of highlighting the focuses and actively seeking methods to innovate 
management actually lead to the low-level management education environment, management method, art and image of managers, which play an imperceptible role in forming management thinking and philosophy of students and cultivating organizational leadership and coordination and further weakening the "management education".What's more, the conventional educational methods can cause the rigid thinking of students and the lack of innovative spirit to a certain extent.

\section{Measures to Improve the Quality of Military Academy Management Education}

\subsection{Focusing on Improving the Overall Quality of People and Establishing Academy Management Education}

Human is always in the important position, the main body of job and innovation among many elements in the management system, and even the most active factor in the management process compared with various teaching facilities, system norms and educational conditions, therefore, only improving the quality of people can lay a solid foundation for management education.

\subsubsection{Establishing the Concept of "Delicacy Education"}

It is very essential to focus on the military struggle preparation, the actual demands of army building and the characteristics and laws of the military academy construction, integrate resources from all aspects, explore the potential, effectively give full play to the roles of teaching education, management education, environmental education and take the intensive, comprehensive, scientific personnel cultivation road.In addition, inviting some excellent military leaders to the school and introducing some management methods and measures of different seasons and periods can enrich the daily management and achieve "the harmony between education and management."

\subsubsection{Establishing the Concept of "Strong Management"}

On the one hand, the academy management education involves teaching, research, personnel and other aspects, meaning manpower, material and financial resources management; on the other hand, the management education can not be completed by few departments and people, and all departments and people are in the management of the organization, therefore, the academies should strengthen the "strong management" concept, effectively combine the management with the central work and make it maintain various links centered by"education".

\subsubsection{Establishing the Concept of "Large-Scale System"}

The academy management education is a complex project that requires the comprehensive, systematic and synchronized instead of the local, decentralized and independent management, and only the formation of a scientific and rational structure can produce a double result. Therefore, it is necessary to build the contents of management education from the overall perspective about the "education".

\subsection{Focusing on Seeking the Best Benefits of Management Education and Building a New Scientific and Efficient Management Education Mechanism \\ 4.2.1 Improving The Level Management Mechanism}

The implementation of the level management is the inevitable requirement for the organizational system to improve the work efficiency and the comprehensive education ability. Each level has its own work and the corresponding specific goals and responsibilities, and the academies should discuss carefully, put forward a reasonable construction program and implement them effectively, including: working according to their own responsibilities, leaders at all levels should manage their own staff and affairs to achieve the integration of responsibilities, rights and interests, avoiding skipping a grade and giving full play to their respective roles.

\subsubsection{Introducing the Performance Management Mechanism}

Performance management is to connect the working performance of various staff with their reward distribution, adjustment and promotion through establishing a set of effective performance management system,and its main purpose is to improve and promote the management performance, strengthen the management objectives and provide a strong support for human resources management. As the place gathering teaching and research personnel, the schools should actively carry out research, evaluate the goal completion and performance of the departments and staff according to the actual requirements of the military academy management, establish the performance files to provide an 
objective basis for the reward distribution, personnel incentives, training, selection and promotion, change the negative working attitudes and improve the practical benefits of management education.

\subsubsection{Improving the Supervision and Inspection Mechanism}

Supervision and inspection is an effective way to supervise the implementation of management education and change the working style through examining,finding and solving the problems and includes: daily supervision and inspection can reflect the regular requirements of management education and focus on the foundation; random supervision and inspection aims to the implementation of a specific stage to ensure the completion of tasks. The establishment of a perfect supervision and inspection mechanism in strict accordance with the standards can effectively promote the continuous development of management education.

\subsubsection{Establishing the Information Feedback Mechanism}

"Act according to circumstances"is very essential.The management object, management environment, management force, management scope, management standard and management condition of the schools will undergo great changes with the development of the times, and grasping the progress of management education and introducing timely and effective new approaches and initiatives according to the new situation and new tasks not only can affect the effectiveness of management education, but the comprehensive construction and development of schools. Therefore, the schools should fully mobilize all positive factors, expand the mass foundation of management education and establish a sensitive and efficient information feedback mechanism in addition to reforming management models, updating management tools, optimizing management methods and broadening the management approaches, which can further enhance its pertinence, effectiveness and authority.

Therefore, the scientific management education work mechanism is constructed through the relevant conclusion and it is shown below:

\section{building a new scientific and efficient management education}

\begin{tabular}{|c|c|c|c|}
\hline $\begin{array}{l}\text { Improving } \\
\text { the level } \\
\text { management } \\
\text { mechanism }\end{array}$ & $\begin{array}{l}\text { Introducing the } \\
\text { performance } \\
\text { management } \\
\text { mechanism }\end{array}$ & $\begin{array}{l}\text { Improving the } \\
\text { supervision and } \\
\text { inspection } \\
\text { mechanism }\end{array}$ & $\begin{array}{l}\text { Establishing } \\
\text { the } \\
\text { information } \\
\text { feedback }\end{array}$ \\
\hline 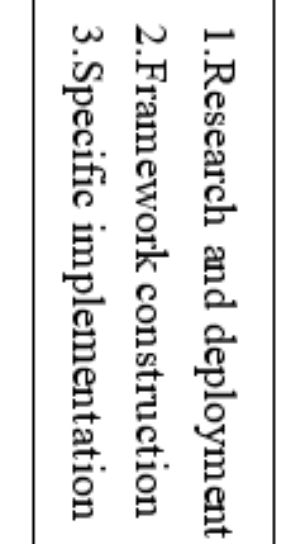 & 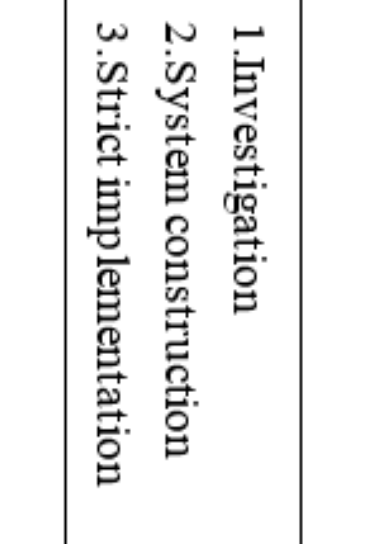 & 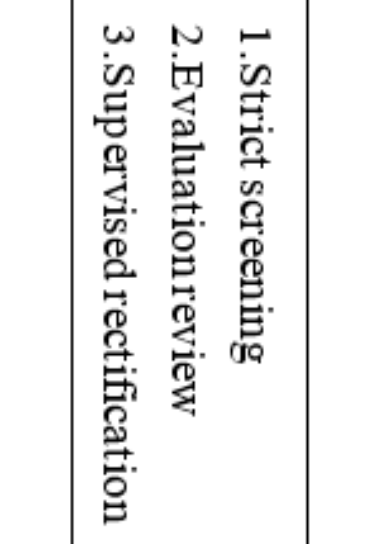 & 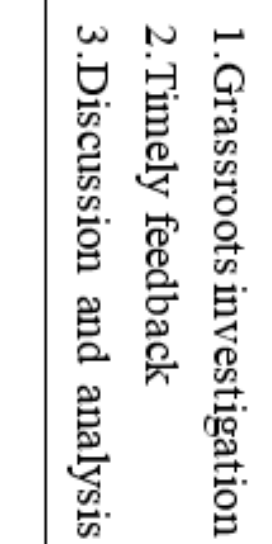 \\
\hline
\end{tabular}




\subsection{Focusing on the Objective Demands for Cultivating New Military Talents and Actively Exploring the New Ways of Academy Management Education 4.3.1 Implementing the"Flexible" Management and Promoting the Comprehensive Development Of Personality}

The military management system is relatively stable, but the implementation ways and methods are different, diverse and flexible in accordance with different situation, and this is the dialectical unity of the principle and flexibility in the management education.

\subsubsection{Improving the "Cultural Management" Concept and Stimulating the Inherent Potential}

Compared with the scientific management, cultural management focuses more on the subjective initiative of people in the management, emphasizes human who is both the starting point and finishing point of management, transforms the main external control into the self-control, the reward and penalty into self-discipline, and hard management into the combination of hard and soft as the soft management better achieves the subjective initiative and promotes the virtuous circle of high-efficient management and high working enthusiasm. Therefore, the requirement of cultural management actually corresponds to the "management education" of military academies, and "education" is the highest level of management educators that can give full play to the subjective initiative, improve people's self-education, self-management abilities and promote better "management education".

\subsubsection{Building the Expert Management Team and Improving the Level of Management Education}

Management level is closely related to the quality of management personnel, and the key to improving the level is to establish a high-quality and professional personnel group engaging in management activities for military academies. The main managers should be equipped with the systematic education science and management knowledge, have the innovative ability and able to provide quality services and reliable protection for the teaching and research; in addition, they must constantly learn new management theories, experience and practices, update management ideas, develop management ideas, enhance management abilities, realize"good management" and ultimately improve the management education level.

\section{Conclusion}

Nowadays, the changing world situation requires us to take the decisions of the Party Central Committee, the Central Military Commission and President Xi Jinping as guiding ideology, reform the development modes conforming to the trend of the times, learn from the reform experience to constantly improve the military personnel training mode and strengthen the training efforts instead of sitting passively, in order to cultivate a modern military personnel team with

\section{References}

[1]. Yin Qi .Accurately Grasp the "Three in One" New Military Personnel Training System [J]. A Study of Army Political Work, 2015, (6).

[2]. .Shi Jing,Fang Jiayin. Scientific Construction of "Three in One" New Military Talents Training System [J]. Continuing Education, 2016, (9).

[3]. Zhou Qiang,Rong Wenhui. Journal of Jiamusi Education Institute [J]. Journal of Jiamusi Education Institute, 2014, (4).

[4]. Zhou Xuejun. On the Educational Innovation of Military Academies [J]. Jiangsu Social Sciences ,2009,(S1).

[5]. Yao Binghong,Hu Shengming. Reflections on Educational Transformation and Construction of Teaching Staff in Military Academies [J]. Journal of Higher Education Research, 2005, (2).

[6]. Wang Yan. Cultivation of Creative Military Talents and Educational Management Reform [J]. Journal of Higher Education Research, 2002, (3). 